\title{
iPads in Breast Imaging - A Phantom Study
}

\author{
iPads in der Brustbildgebung - eine Phantomstudie
}

Authors

Affiliation
M. Hammon*, P. M. Schlechtweg*, R. Schulz-Wendtland, M. Uder, S. A. Schwab

Department of Radiology, University Hospital Erlangen, Erlangen

\author{
Key words \\ - mammography \\ - iPad \\ - CDMAM phantom \\ - patient consultation \\ - education/teaching \\ Schlüsselwörter \\ - Mammografie \\ - iPad \\ - CDMAM-Phantom \\ - Patientenkonsultation \\ - Ausbildung/Lehre
}

\section{received 26.9.2013 \\ revised 29.11.2013 \\ accepted 2.12.2013}

\section{Bibliography}

DOI http://dx.doi.org/

10.1055/s-0033-1360184

Geburtsh Frauenheilk 2014; 74 :

152-156 @ Georg Thieme

Verlag KG Stuttgart · New York . ISSN 0016-5751

\section{Correspondence}

\section{Dr. Matthias Hammon, MD}

University Hospital Erlangen

Department of Radiology

Maximiliansplatz 1

91054 Erlangen

matthias.hammon@

uk-erlangen.de

\section{Abstract \\ V}

Introduction: Modern tablet PCs as the iPad are becoming more and more integrated into medicine. The aim of this study was to evaluate the display quality of iPads regarding digital mammography. Materials and Methods: Three experienced readers compared the display quality of the iPad 2 and 3 with a dedicated 10 megapixel (MP) mammography liquid crystal display (LCD) screen in consensus using the standardized Contrast Detail Mammography (CDMAM) phantom. Phantom fields without agreement between the readers were classified as "uncertain", correct 2:1 decisions were classified as "uncertain/readable". In a second step display quality of the three reading devices was judged subjectively in a side by side comparison.

Results: The 10 MP screen was superior to both iPads in 4 (phantom-)fields and inferior in 2 fields. Comparing the iPads, version 3 was superior in 4 fields and version 2 was superior in 1 field. However these differences were not significant. Total number of "uncertain" fields did not show significant differences. The number of "uncertain" fields was 15 with the $10 \mathrm{MP}$ screen, 16 with the iPad 2 and 17 with the iPad $3(p>0.05)$, the number of "uncertain/readable" fields was 4,7 and 8 , respectively. Subjective image quality of the iPad 3 and the 10 MP screen was rated superior to the iPad 2. Conclusion: The evaluated iPads, especially in version 3 , seem to be adequate to display mammograms in a diagnostic quality and thus could be useful e.g. for patient consultation, clinical demonstration or educational and teaching purposes. However primary mammogram reading should still be performed on dedicated large sized reading screens.

\footnotetext{
* Both authors contributed equally to this work.
}

\section{Zusammenfassung \\ $\nabla$}

Einleitung: Moderne Tablet PCs wie das iPad finden zunehmend Einzug in die Medizin. Ziel dieser Arbeit war es, die Bildschirmqualität von iPads bezüglich ihrer Eignung zur Darstellung von Mammografien zu evaluieren.

Material und Methodik: Drei erfahrene Befunder verglichen im Konsens die Bildschirmqualität des iPad 2 und des iPad 3 mit einem 10-Megapixel (MP-)Mammografie-Flüssigkristallbildschirm anhand des standardisierten Contrast-Detail-Mammography-(CDMAM-)Phantoms. Felder ohne Übereinstimmung der Befunder wurden als „unsicher“, korrekte 2:1-Entscheidungen als „unsicher/befundbar" klassifiziert. In einem weiteren Schritt wurde die subjektive Bildschirmqualität der 3 Geräte bewertet.

Ergebnisse: Der 10-MP-Bildschirm war beiden iPads in 4 (Phantom-)Feldern überlegen und in 2 Feldern unterlegen. Im Vergleich der beiden iPads untereinander war die Version 3 bei 4 Feldern und Version 2 bei einem Feld überlegen. Diese Unterschiede waren nicht signifikant. Die Anzahl unsicherer Felder betrug 15 beim 10-MP-Bildschirm, 16 beim iPad 2 und 17 beim iPad 3 ( $p>0,05$ ), die Anzahl der unsicher/befundbaren Felder betrug hierbei 4,7 bzw. 8. Die subjektive Bildschirmqualität des iPad 3 und des 10-MP-Bildschirms wurde besser bewertet als die des iPad 2 .

Schlussfolgerung: Die evaluierten iPads, insbesondere in der Geräteversion 3, erscheinen für die hochaufgelöste Darstellung von Mammografien, z.B. für Patientenkonsultationen, klinische Demonstrationen oder Ausbildungs- und Lehrzwecke technisch geeignet. Die primäre Befundung von Mammografien sollte nach Meinung der Autoren jedoch unbedingt mit dedizierten Mammografie-Befundungsmonitoren erfolgen. 


$\begin{array}{ll}\text { Abbreviations and Acronyms } \\ \text { MRI } & \text { Magnetic Resonance Imaging } \\ \text { TC } & \text { Tablet Computers } \\ \text { FFDM } & \text { Full Field digital Mammography } \\ \text { PACS } & \text { Picture Archiving and Communication } \\ & \text { System } \\ \text { CDMAM phantom } & \text { Contrast Detail Mammography Phantom }\end{array}$

\section{Introduction}

$\nabla$

Breast cancer is the most frequent cancer in women in the world. It accounts for $23 \%$ of all female cancers [1,2]. Imaging techniques, such as mammography, digital tomosynthesis, ultrasound and magnetic resonance imaging (MRI) play a major role in breast diagnostics. Especially mammography is crucial for the early detection of breast cancer which allows a decrease in mortality by $15 \%$ [3]. Therefore screening mammography is recommended every 2-3 years for women older than 50 in many countries $[4,5]$. Well-trained radiologists and technicians as well as high-quality technical equipment are required to properly perform breast diagnostics.

Traditionally a film-based method mammography has nowadays virtually been replaced by digital techniques which imply the possibility of direct on-screen reading. Whilst for decades computers consisted of a distinct separation of user interface (e.g. keyboard and/or computer mouse) and reading unit which is the monitor, modern tablet computers (TC) are becoming increasingly popular [6]. Especially the introduction of the $\mathrm{iPad}^{\circledR}$ by Apple (Cupertino, California, USA) in 2010 was a decisive moment in the development of this technology, but other manufacturers and operating systems, such as Google's Android (Mountain View, California, USA), were also able to gain a foothold in the market. As the screen serves as both user interface and reading unit, TCs such as the iPad provide a high level of mobility and universal employability and therefore became of interest for image reading as well as for educational purposes [7-13]. However, to the best of our knowledge, no studies have been conducted so far in the field of breast imaging. Using the iPad could be a feasible way to customize the highly-demanded tasks of patient consultations, clinical demonstrations or educational and teaching purposes.

As digital mammography is one of the most demanding imaging modalities in terms of image resolution, the purpose of this study was to evaluate the display quality with a standardized phantom on the iPad 2 and the iPad 3 in comparison to a dedicated 10 megapixel mammography screen and thus to determine if modern TCs such as the iPad can serve as mobile and user-friendly devices for non-diagnostic mammography reading purposes.

\section{Materials and Methods \\ $\nabla$}

This investigation was conducted in coordination with the local institutional review board.

\section{Contrast Detail Mammography (CDMAM) phantom}

For phantom studies we X-rayed the well-known Contrast Detail Mammography (CDMAM) phantom (version 3.4, Artinis Medical Systems B.V., AS Zetten, the Netherlands) ( Fig. 1). The phantom consists of an aluminum base with gold discs of various thickness

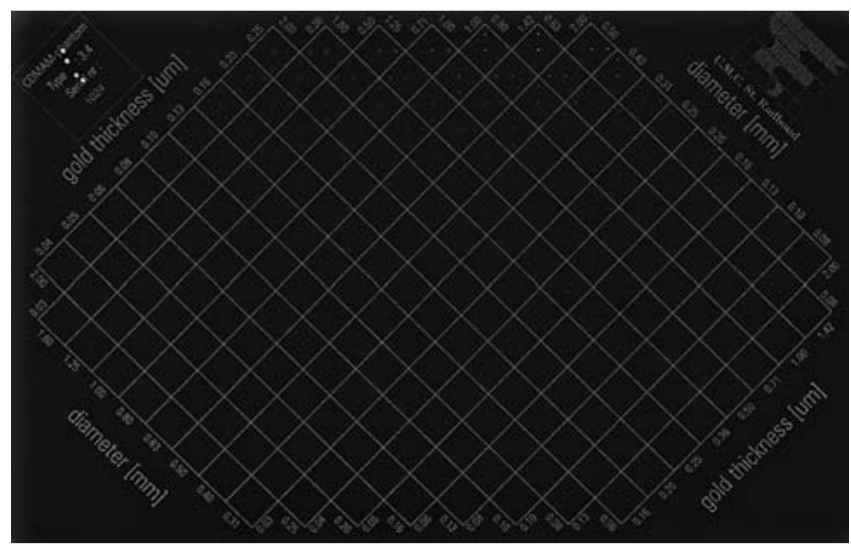

Fig. 1 Contrast Detail Mammography (CDMAM) phantom was X-rayed for phantom studies. It consists of an aluminum base with gold discs of various thickness and diameter. The gold discs are arranged in a matrix of 16 rows by 16 columns. Within a row the disc diameter is constant, with increasing thickness, and within a column the thickness off the discs is constant and the diameter increases. The thickness is between 0.03 and $2.00 \mu \mathrm{m}$ and the diameter is 0.06 between $2.0 \mathrm{~mm}$.

and diameter. The gold discs are arranged in a matrix of 16 rows by 16 columns. Within a row the disc diameter is constant, with (partly) logarithmic increasing thickness. Within a column the thickness of the discs is constant and the diameter increases logarithmically. The thickness is between 0.03 and $2.00 \mu \mathrm{m}$ and the diameter between 0.06 and $2.0 \mathrm{~mm}$. Each field contains two identical discs (same thickness, same diameter), one in the center and one in a randomly chosen corner. The matrix grid is silkscreen printed with X-ray contrasting paint and the aluminum base is attached to a Plexiglas cover $[14,15]$. The observer visibly determines the field with the gold discs at each contrast level that is barely detectable in the image. This phantom analysis allows the evaluation of spatial resolution, contrast, and noise associated with the mammography device.

\section{Image acquisition}

Contrast Detail Mammography (CDMAM) phantom was X-rayed with a full field digital mammography (FFDM) system (Mammomat Inspiration ${ }^{\circledR}$, Siemens, Erlangen, Germany) on an anode/filter combination of tungsten/rhodium using automated dose regulation. Image data were stored in the well established DICOM (Digital Imaging and Communications in Medicine) format.

\section{Devices and data analysis}

We used a commercially available iPad 2 and iPad 3 (Apple, Cupertino, California, USA) and a 10 megapixel 30-inch LCD screen (Coronis Fusion $10 \mathrm{MP}$, Barco, Kortrijk, Belgium). The iPad screen is about 9.7 inches diagonally in size (about $24.6 \mathrm{~cm}$ ) in both versions. The iPad 2 comes with a resolution of $1024 \times 768$ at 132 pixels per inch (ppi) whereas the iPad 3 has a screen resolution of $2048 \times 1536$ at 264 pixels per inch (ppi). The readers (three radiologists with work experience in breast imaging of 11, 5.5 and 3.5 years) interacted directly on the iPad's touch screen display (e.g. zooming in or out) using either their fingertips or a dedicated pen (Kensington, Redwood Shores, California, USA). The DICOM data of the X-rayed CDMAM phantom were displayed with the Syngo Plaza ${ }^{\circledR}$ software (Siemens AG, Erlangen, Germany) on the $10 \mathrm{MP}$ screen and with the OsiriX software (OsiriX, version 5.0.2, OsiriX Foundation, GNU General Public License) on both 


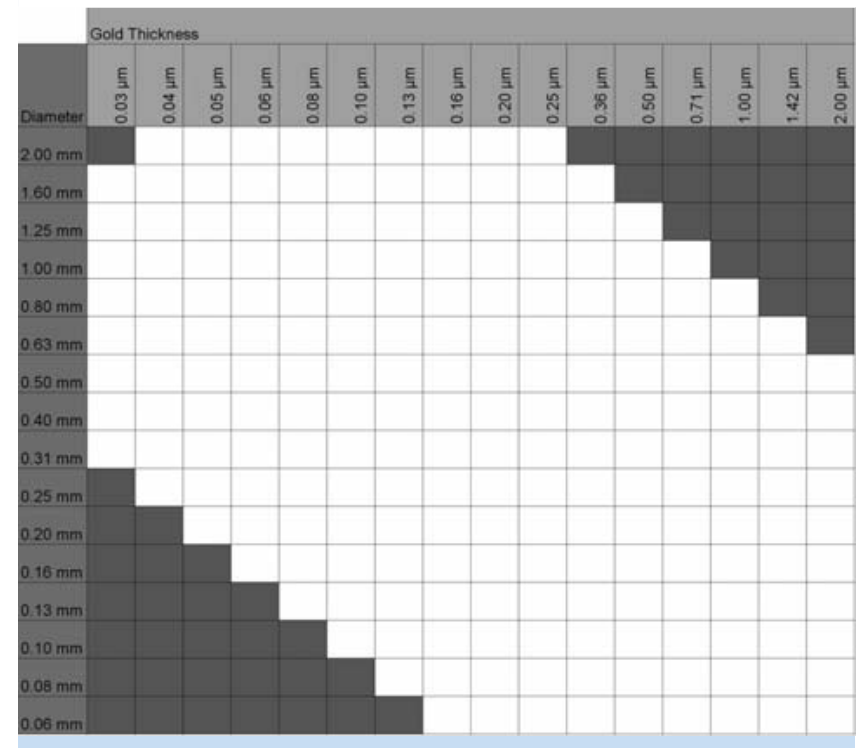

Fig. 2 Blanco evaluation form used for consensus reading of the Contrast Detail Mammography (CDMAM) phantom on each reading device.

iPads. No image information was added or removed. The phantom images were visually analyzed by the 3 readers in consensus in a routine breast imaging workplace with dedicated standard illumination. The result (= position of the gold pallets in 3, 6, 9 or 12 o'clock position) was documented for each field of the phantom on a purpose-built form ( $\bullet$ Fig. 2). If there was no agreement between the readers regarding the correct marker position ( $2: 1$ decisions), the field was considered as uncertainty and the marker position of the majority (the two agreeing readers) was chosen. In case of total disagreement $(1: 1: 1)$ or if the readers agreed that the markers could not be detected anymore the field was considered as "non readable". Afterwards results were checked in regard to correctness, a correct field was classified as "readable".

Additionally the phantom was reviewed again at the end of the study in consensus on all three devices side by side ( $\bullet$ Fig. 3 ) to judge the subjective image quality in direct comparison (1 to 6; 1 = excellent quality; 6 = bad quality).

\section{Statistical analysis}

Statistical analysis was performed using SPSS (version 15.0, SPSS Inc., Chicago, IL, USA). Student's t-test was applied. A p-value $<0.05$ was considered as significant.

\section{Results \\ $\nabla$}

\section{Technical realization}

During the evaluation no technical problem occurred. The CDMAM phantom could be assessed on the three devices without any limitation.

\section{Objective display quality}

When using the 10 megapixel screen the gold disc position was assessed correctly in 105 of 205 phantom fields (=51.2\% readable). 102 of 205 fields were assessed correctly in the case of iPad $3(=49.8 \%$ readable) and 99 of 205 in the case of iPad $2(=48.3 \%$ readable) ( $\odot$ Fig. 4 a).

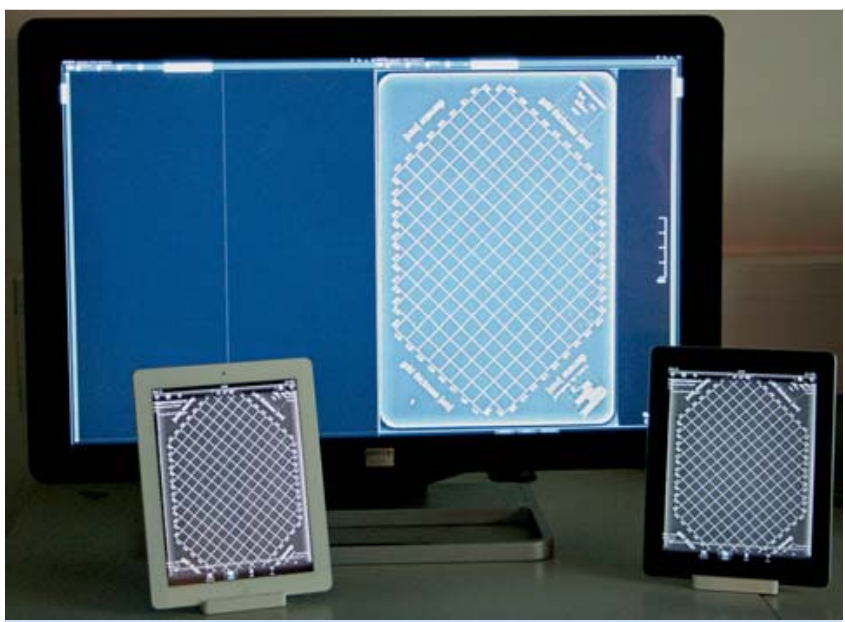

Fig. 3 Contrast Detail Mammography (CDMAM) phantom displayed on the dedicated 10 megapixel screen and on the iPads (version 2 [white] on the left and version 3 [black] on the right side).

In comparison to both iPads assessment with the $10 \mathrm{MP}$ screen lead to additional correctly detected gold disc position in four phantom fields (10 MP screen superior in four phantom fields). In contrast to the $10 \mathrm{MP}$ screen, the iPads allowed the correct detection of the gold disc position in two different phantom fields (iPad screens superior in two phantom fields). Comparing both iPad screens, the results of version 3 were superior in four phantom fields and version 2 was superior in just one phantom field ( Fig. 4b). However, none of these differences were significant $(\mathrm{p}>0.05)$.

In case of a non-agreement between the readers ( $2: 1$ decision), the phantom field was considered as uncertainty. Evaluation uncertainties occurred for all screens. In the case of the 10 megapixel screen 15 fields were uncertain. In the case of the iPad screens, 16 uncertainties occurred with version 2 and 17 with version 3 . The differences between the devices were not significant $(p>0.05)$. The number of uncertain but readable fields ( $t$ wo correct decisions versus one incorrect decision) was four with the $10 \mathrm{MP}$ screen, seven with the iPad 2 and eight with the iPad 3 screen ( $\bullet$ Fig. 4 a).

\section{Subjective display quality}

Subjective image quality assessment favored the iPad 3 and 10 MP screen over the iPad 2. Image quality of the iPad 3 and the $10 \mathrm{MP}$ screen was judged as comparable.

\section{Discussion}

$\nabla$

The purpose of this study was to collect first experiences as to whether or not modern tablet computers (TCs) such as the iPad can be deployed in mammographic imaging. We compared two versions of the tablet PC with a high-quality dedicated 10 megapixel LCD screen concerning display quality. Our results showed that subjective image quality was moderately worse in the case of the iPad 2 and, although not significant, both evaluated iPad versions were slightly inferior to a dedicated $10 \mathrm{MP}$ reading screen in detecting finer contrast details of a standardized mammography phantom. Therefore and as the iPad's 9.7-inch screen is not suitable for primary mammographic reading, especially not for side by side assessment, iPads should not be used for pri- 
iPad 2
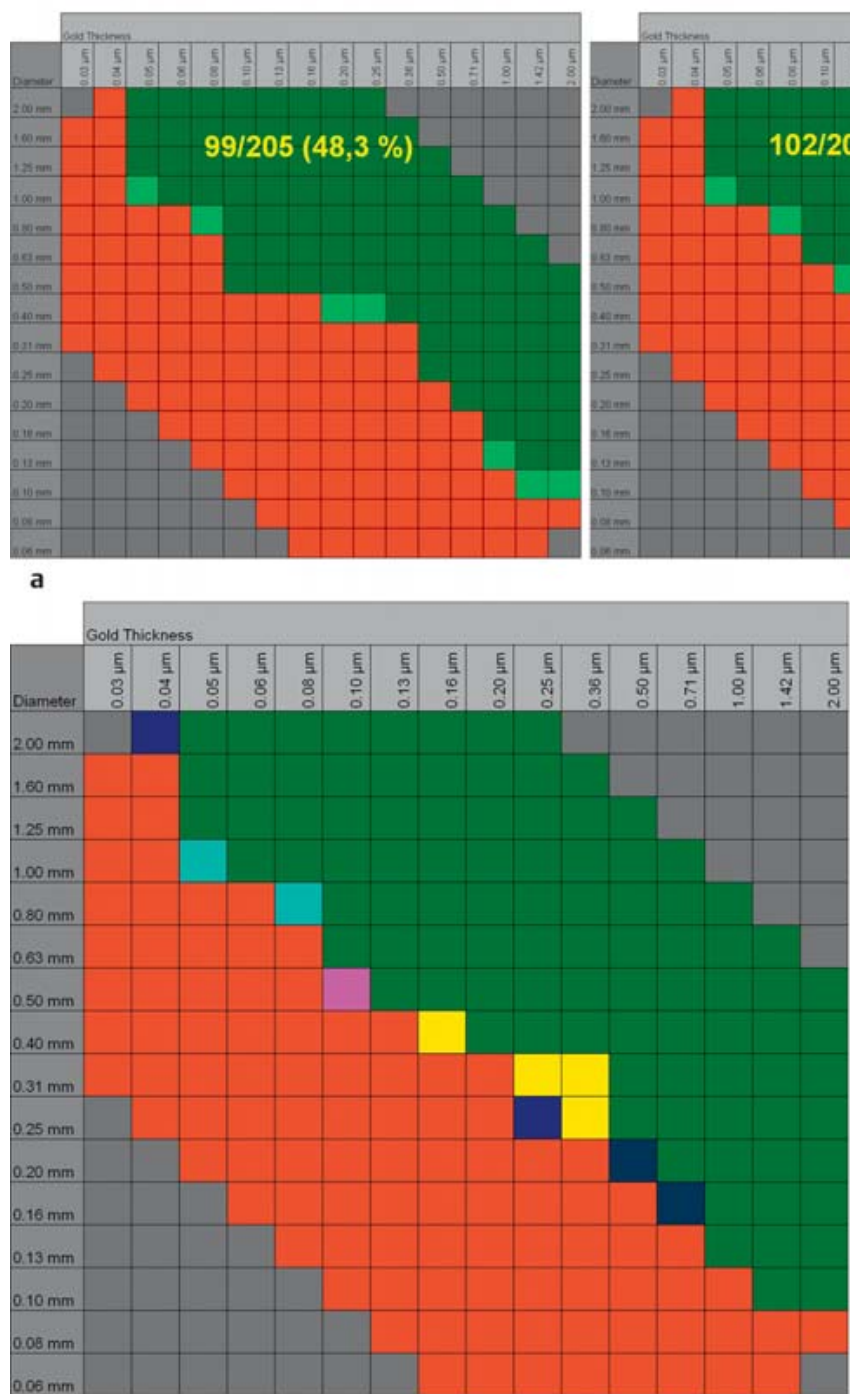

b

Fig. $\mathbf{4 a}$ and $\mathbf{b}$ a Phantom interpretation results of consensus decisions are shown for the three devices. Numbers/percentages of readable phantom fields are shown. Dark green = readable; red $=$ non readable; light green $=$ uncertain but readable (2:1 decisions).
iPad 3
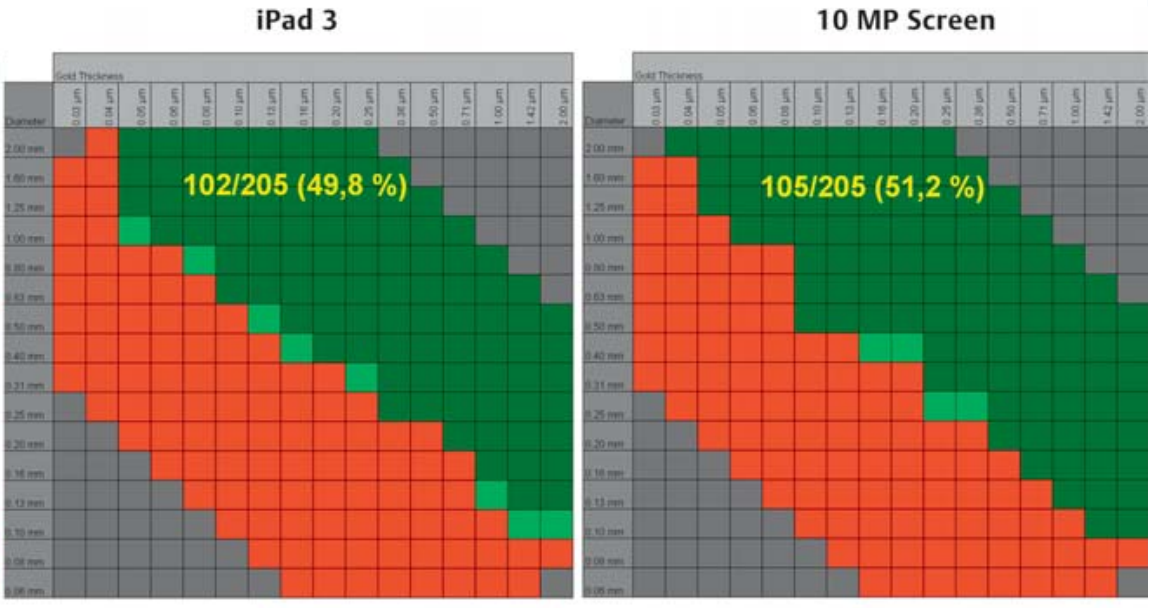

10 MP Screen 
based image evaluation on a mobile device in particular makes image presentation to colleagues much easier. Moreover, TCs such as the iPad facilitate education and self-improvement in breast imaging because more and more dedicated applications are available $[23,24]$.

As mammography is one of the most demanding imaging modalities in terms of display resolution the results of our study suggest that for these purposes the iPad's screen quality is sufficient not only in breast imaging but also for other radiological fields such as CT, MRI, ultrasound or even plain film radiography of any body region.

Some limitation needs to be addressed. As this was a phantom based study we are aware that further clinical investigations need to be conducted to prove our results. However, in this study, we wanted to report first experiences with tablet PCs regarding mammogram interpretation and the results from our phantom evaluation suggest that the iPad's screen quality should be sufficient to utilize it for displaying mammograms e.g. during patient consultations or for education purposes. A clinical follow-up study including lesion-free mammograms and mammograms showing pathologies, such as invasive ductal carcinoma or DCIS could prove this. Moreover, it should analyze to what extent individual factors such as breast density or lesion size and type have an influence on the interpretation performance.

The benefits of iPad-based patient consultations, novice reader education or clinical demonstration have to be confirmed in greater detail on a larger patient number and acceptance among clinical colleagues and patients should be investigated. It is important to note that country-specific legal frameworks, such as data protection guidelines, need to be taken into consideration when the tablet PCs are used, especially concerning data transmission (cloud, etc.).

The assessment of mammograms requires comparison with prior examinations or with the contralateral breast in a side-by-side fashion. However, as the iPad's screen size does not allow the display of multiple mammograms at once in a diagnostic size, sideby-side reading may not be recommended. Moreover, as the screen resolution of the evaluated TCs does not meet the national legal requirements, primary mammography reading must not be performed on TCs. Nevertheless this could change in the future with further technical development.

\section{Conclusions}

$\nabla$

Modern tablet computers (TCs) such as the iPad are promising devices for medical purposes due to their straightforward user interface, broad employability and mobility. Our results show that TCs seem suitable for displaying mammograms for a variety of tasks such as patient consultation, clinical demonstrations or educational and teaching purposes. Nevertheless, to perform primary mammogram reading as well as follow-up and side by side assessment, a large screen with a high resolution meeting the legal requirements is necessary.

\section{Acknowledgements}

$\nabla$

The authors thank Evelyn Wenkel for support with the imagework and Martina Wabel for excellent collaboration of gynaecologic radiology.

\section{Conflict of Interest}

\section{$\nabla$}

None.

\section{References}

1 International Agency for Research on Cancer. 2008. Online: http:// globocan.iarc.fr/factsheets/populations/factsheet.asp?uno=900; last access: 25.09.2013

2 World Health Organization. 2012. Online: http://www.who.int/cancer/ detection/breastcancer/en/index1.html; last access: 25.09.2013

3 Gøtzsche PC, Nielsen M. Screening for breast cancer with mammography. Cochrane Database Syst Rev 2011; 1: CD001877

4 U.S. Preventive Services Task Force. Online: http://www.uspreventiveservicestaskforce.org/uspstf/uspsbrca.htm; last access: 25.09.2013

5 European Parliament. Online: http://www.europarl.europa.eu/sides/ getDoc.do?pubRef=-//EP//TEXT+IM-PRESS+20100419IPR73048+0 +DOC+XML+V0//EN; last access: 25.09.2013

6 Coldewey D. Apple: 100 million iPads sold. nbcnews.com 2012. Online: http://www.nbcnews.com/technology/gadgetbox/apple-100-millionipads-sold-1C6619845; last access: 25.09.2013

7 Mc Laughlin P, Neill SO, Fanning $N$ et al. Emergency CT brain: preliminary interpretation with a tablet device: image quality and diagnostic performance of the Apple iPad. Emerg Radiol 2012; 19: 127-133

8 John S, Poh ACC, Lim TCC et al. The iPad tablet computer for mobile oncall radiology diagnosis? Auditing discrepancy in CT and MRI reporting. J Digit Imaging 2012; 25: 628-634

9 Sadri A, Murphy AD, Odili J. iPad local flap pre-operative planning: a good training tool. J Plast Reconstr Aesthet Surg 2012; 65: 1746

10 Richardson ML, Petscavage JM, Hunter JC et al. Running an online radiology teaching conference: why it's a great idea and how to do it successfully. Acad Radiol 2012; 19: 746-751

11 Korbage AC, Bedi HS. The iPad in radiology resident education. J Am Coll Radiol 2012; 9: 759-760

12 McNulty JP, Ryan JT, Evanoff MG et al. Flexible image evaluation: iPad versus secondary-class monitors for review of MR spinal emergency cases, a comparative study. Acad Radiol 2012; 19: 1023-1028

13 Johnson PT, Zimmerman SL, Heath D et al. The iPad as a mobile device for CT display and interpretation: diagnostic accuracy for identification of pulmonary embolism. Emerg Radiol 2012; 19: 323-327

14 Bijkerk KR, Lindeijer JM, Thijssen MAO. The CDMAM phantom: a contrast detail phantom specifically for mammography. Radiology 1993; 185: 395

15 Artinis Medical Systems B.V. Homepage. Online: http://www.artinis. com/product/cdmam_34; last access: 25.09.2013

16 Philippe $F$, Meney $M$, Larrazet $F$ et al. Effects of video information in patients undergoing coronary angiography. Arch Mal Coeur Vaiss 2006; 99: 95-101

17 Schlechtweg PM, Hammon M, Heberlein C et al. Can the documented patient briefing be carried out with an iPad app? J Digit Imaging 2013; 26: 383-392

18 Beamond BM, Beischer AD, Brodsky JW et al. Improvement in surgical consent with a preoperative multimedia patient education tool: a pilot study. Foot Ankle Int 2009; 30: 619-626

19 Mulsow JJW, Feeley TM, Tierney S. Beyond consent - improving understanding in surgical patients. Am J Surg 2012; 203: 112-120

20 Eggers C, Obliers R, Koerfer A et al. A multimedia tool for the informed consent of patients prior to gastric banding. Obesity (Silver Spring) 2007; 15: 2866-2873

21 Schlechtweg PM, Kuefner MA, Heberlein C et al. A useful tool for routine radiological examinations: the iPhone application "KM Helper". Radiologe 2011; 51: 392-396

22 Abboud S, Weiss F, Siegel E et al. TB or Not TB: interreader and intrareader variability in screening diagnosis on an iPad versus a traditional display. J Am Coll Radiol 2013; 10: 42-44

23 Statdx. Online: http://www.statdx.com; last access: 25.09 .2013

24 Radiology Assistant. Online: http://www.radiologyassistant.nl; last access: 25.09 .2013 